\title{
¿EL MOZART ESPAÑOL?
}

JORGE VELAZCO

La familia de don Juan Simón de Arriaga (1766-1836) tuvo un gran prestigio en Bilbao durante el siglo xviII. El propio Juan Simón era un destacado miembro de la comunidad bilbaína y había logrado el arraigo de una muy favorable situación económica y social, a partir de su próspero negocio de transporte marítimo, que contaba, para dar los servicios que ofrecia, con toda una flota de buques mercantes cubriendo las rutas marítimas del comercio entre Francia y el norte de España. Sus negocios lo habían hecho rico y prominente, pero no lo habían alejado de su afición y devoción artística primordial: el cultivo intenso y profundo de la música, que seguía con un fervor hispánico, similar al de los niveles de alucinación que pueden alcanzar, a veces, los aficionados a los toros. De suyo, don Juan Simón había llegado tan lejos como a trabajar en calidad de músico profesional (pese al disfraz de servicio a los actos de culto religioso), al tocar públicamente el órgano y el clavecín en la iglesia de Berriatúa, pequeño pueblo de la provincia de Vizcaya, que en su época no debe haber tenido más allá de 1500 habitantes. Con rigor, se debería hablar de la anteiglesia de Berriatúa, nombre por el cual se conocen tanto las iglesias parroquiales, como los pueblos y municipios de las provincias vascongadas. No lejos de allí se halla el pueblo de Arriaga, agregado al ayuntamiento de Bilbao, que a pesar de sus 1300 habitantes había producido varios importantes hombres de negocios con el apellido propio del pueblo, entre los que se hallaba don Juan Simón de Arriaga.

Bilbao conoció durante los siglos xvIII y xIx una prosperidad que fundamentó los sólidos cimientos de su importancia presente, en todos los campos del intercambio mercantil. El comercio, la industria naval y el transporte, florecieron al par que sus industrias mineras. La Es. cuela Náutica tenía tanto auge como las minas de hierro, las fundicio nes de acero y toda la industria extractiva de Somorrostro. Las escuelas de comercio, las escuelas normales, fueron antecedente (casi concomitante) de los institutos culturales de la ciudad, entre los que figuró muy importantemente el de artes.

En ese contexto de gran riqueza, familiar, industrial y social, nació uno de los más dotados y capaces compositores en esa nación de crea- 
dores extraordinarios que cuenta entre sus hijos a músicos del tamaño de Victoria, Soler, Albéniz y Falla.

Juan Crisóstomo Jacobo Antonio de Arriaga y Balzola nació en Bilbao, el 27 de enero de 1806, en el negociohabitación de su padre, ubicado en el número 14 de la calle de Somera. Su apellido, vasco a morir, podría significar algo así como "lugar pedroso", ya que arri supone significar "roca" y aga es el denominador para "lugar" o sitio". El Balzola materno podría venir de más de un lugar y, en vista de la estructura patriarcal española, debemos omitir cualquier comentario respecto de su origen y trayectoria. Algunos autores, americanos, ingleses y hasta españoles, han señalado la coincidencia con los nombres bautismales de Arriaga y el hecho de que su padre, músico de profunda devoción al arte, habría notado que su hijo nació en el quincuagésimo aniversario del nacimiento de Mozart y que, por lo tanto, habría decidido bautizarlo con los dos primeros nombres del infinito compositor, como un homenaje al salzburgués, e incluso como un presentimiento y un deseo de su genio musical y también como una premonición de su temprana muerte e ingrata frustración de su talento creador. Pero es más probable que esta curiosa coincidencia no haya tenido más causa que el hecho de que el día de nacimiento de Arriaga se celebra a San Juan Crisóstomo y que, de acuerdo a la inveterada costumbre española, había que poner al niño el o los nombres del santo patrono del día de su nacimiento.

Las aficiones y conocimientos paternos, junto con los desahogados medios económicos de la familia, rindieron pronto un fruto natural, casi esperado, y el niño Juan Crisóstomo Antonio principió a recibir lecciones de música de su padre, apenas tuvo edad para poder comprender algunas de sus estructuras básicas. Además, una facilidad genuina y asombrosa para el manejo de este arte se manifestó desde una edad muy temprana. Se dice que la música era su juego preferido y que comenzó a componer a los nueve años de edad. No solo escribía música, sino que también realizó una verdadera hazaña cuando tenía diez años, ya que tocaba el segundo violín en un cuarteto de cuerdas de adultos, que hacía presentaciones en Bilbao, cuyo único elemento que los diferenciaba de los profesionales era el hecho de que no se ganaban la vida tocando en público. Por lo demás, en cuanto a enfoque y capacidad, las actividades del cuarteto tenían toda la seriedad requerida para lograr merecidamente el apelativo de profesionales. Por 
otra parte, al ojo del historiador, esa temprana vida profesional (al igual que en el caso de Albéniz, si bien en otras dimensiones y áreas) debe haber tenido la influencia evidente en el interés y aptitud para la composición de sus cuartetos de cuerdas, hechos tan sólo ocho años después del principio de sus aventuras como ejecutante público.

Las composiciones de Arriaga presentan varias dificultades para su arreglo, digestión y análisis, ya que no hay una cronología precisa de ellas y que, al parecer, mucha de su obra está perdida. E1 trabajo más antiguo que de él sobrevive es una ópera titulada Nada y mucho, ensayo en octeto, que puede por lo menos calificarse de ambiciosa, ya que se trata de la obra de un niño de once años. La presencia de una guitarra y una trompeta en la peculiar dotación de cuerdas con piano de esta obra, tal vez deba su existencia a los músicos disponibles para tocarla, más que a una influencia determinada y evidente de Boccherini. Sin embargo, no debe descartarse la persistencia en España de los originales conceptos de la textura sonora del italiano, que siempre inquietan cuando aparecen en cualquier forma, si bien el galimatías de piano y guitarra que tiene la obra no puede explicarse sino por la existencia de personas, vinculadas con la obra, que tocaban esos instrumentos. Después nos hallamos su Obertura op. 1, dedicada a la Academia Filarmónica de Bilbao y expresada en instrumentación para noneto, cuya peculiar integración hace pensar en la posibilidad de que la socialmente prestigiosa institución bilbaína haya tenido nueve socios que tocaban un abigarrado conjunto de instrumentos: flauta, dos clarinetes, dos trompetas, dos violines, viola y contrabajo. Esta obra surgió cuando Arriaga tenía doce años, periodo en el que también compuso una cantata Patria y una Marcha Militar para banda.

A sus trece años, tienen lugar los acontecimientos musicales que deciden la vida de Arriaga, ya que compone tanto y tan bueno, que la conveniencia de proseguir una carrera musical se hace muy evidente y obliga a su familia y a él mismo a proceder en consecuencia. Arriaga compone su segunda obra escénica, una ópera sobre un libreto del poeta dramático español Francisco Comella (1716-1779), entonces en el apogeo de su fama como creador, que lleva el curioso título de Los esclavos felices. La ópera fue compuesta cuando nuestro precoz autor tenía trece años, su obertura escrita después de que el compositor terminó las escenas vocales y la obra completa se estrenó en 1820 , con la no sólo entusiasta sino delirante aprobación y aceptación de la comu- 
nidad cultural de Bilbao, desde su primera representación. El éxito de su ópera preparó el campo para la aparición del Tema variado en cuarteto, op. 17 (sin que podamos saber qué fueron los quince números de opus entre su Obertura para noneto y esta obra); La húngara, para violín y contrabajo; La húngara en cuarteto y un Stabat Mater para voces y orquesta.

Después de que Arriaga cumplió quince años, sus padres tomaron la decisión de mandarlo a la meca cultural de Europa, con el objeto de lograr el desarrollo pleno del gran talento que el destino había llevado a su familia. En octubre de 1821, Arriaga comenzó sus cursos en el Conservatorio de París, después de haber hallado un tranquilo -y costoso- lugar para vivir, en la Rue Saint Honoré 314, no muy lejos de los Campos Elíseos y de las Tullerías. Un curioso paralelo histórico puede ser establecido aquí, ya que el joven Berlioz, tan sólo unos años màor que Arriaga, llegó a París en el mismo año, si bien obtuvo alojamiento bastante más modesto. Las actitudes familiares eran también diametralmente opuestas en el caso de Arriaga, ya que el joven Héctor venía a estudiar medicina en París, y tanto al doctor Berlioz como a su esposa les tenían sin cuidado las inclinaciones de su hijo; él débía lograr un título que le permitiera convertirse en un miembro respetado - y respetable - de un modo de pensar en el que el ejercicio profesional del arte se consideraba pecaminoso, inmoral o simplemente estúpido, una especie de muerte civil y una maldición social que condenaba a sus practicantes a la segregación y la miseria. Durante los años que Berlioz tardó en lograr su independencia financiera y emocional para poder seguir su vocación artística, que era vehementemente reprimida por sus padres, Arriaga contaba con el apoyo afectivo, social y económico de los suyos; así como con la más ferviente admiración de sús maestros, lo cual tampoco era la especialidad de Berlioz. Fue hasta el mes de agosto de 1826, medio año después del entierto de Arriaga, que Berlioz pudo inscribirse como alumno regular de tiempo completo en el Conservatorio de París.

En cambio, entre 1821 y 1826, Arriaga estudió violín con Baillot y armonfa con Fétis. Este último se sintió satisfecho con el avance logrado por su alumno en tres meses y lo enroló en la clase de contrapunto. En dos años, Arriaga dominó la fuga y el contrapunto, tal y como eran enseñados en el Conservatorio de París, y logró una gran eficiencia como ejecutante de violín. En 1823 ganó el segundo premio del Con- 
servatorio en las mencionadas materias y su ejercicio de examen final, hecho un año después, la musicalización de la conclusión Et vitam venturi" Saeculi, del Credo, a ocho voces reales (ahora perdido), Iogró la entusiasta admiración del director de la institución, el maestro Luigi Cherubini (envidioso, chauvinista francés delirante -fue quien le negó a Franz Liszt el ingreso al Conservatorio basado en su nacionalidadpese a su propia calidad jurídica, sociológica y artística de italiano), quien lo nombró de inmediato en 1824 répétiteur -instructor- de una classe de répétition de armonía y contrapunto. Arriaga tenia entonces solamente dieciocho años de edad y, tal como dijo Fétis, su ansia de trabajo no conocía medida ("... la necesidad de producir lo atormentaba, como sucede con todo hombre de genio") .

Fétis dijo también que "... aprendió los primeros elementos de su arte casi sin maestro, guiado por su genio" y que "sólo tres meses fueron necesarios para darle un conocimiento perfecto de la armo. nia" ya que "Arriaga había recibido de la naturaleza dos facultades que raramente se encuentran combinadas en un solo artista: el don de la invención y el dominio completo de todas las dificultades del oficio". Está veneración de su maestro, incrementada un tanto por la temprana muerte de su alumno (son opiniones vertidas en su obituario, escrito por Fétis), han hecho que se intente disminuir sus logros con la explicación de que las obras previamente compuestas prueban una comprensión pragmática de la composición, por lo que su formalización teórica habría sido necesariamente muy sencilla, e incluso trivial, pese a que la instrucción formal que pudo haber obtenido en Bilbao se apunta como muy incompleta. El hecho de que Fétis parecía pensar que Arriaga tenía dos años menos de los que en realidad cumplía, ha servido para dar mayor abundamiento a la teoría de que debe haberse exagerado la ignorancià del muchacho con el objeto de hacer destacar su talento y poderlo presentar con mayores dimensiones, ya que la información de Fétis debía provenir del mismo Arriaga o sus patrocinadores o padres.

Con independencia de lo fútil y lo imposible que resulta intentar una escala para medir el talento artístico, cuyos resultados expresivos son tan dependientes de la moda, la elocuencia de la obra de Arriaga habla muy claramente de una facilidad extraordinaria y un talento muy fuera de lo común. Pasa muchas veces (tal vez siempre o casi siempre) que el verdadero talento simula el aprendizaje rápido, el talentoso 
parece saberlo todo de antemano, dando la impresión de aprender sin esfuerzo lo que a otros - no necesariamente torpes- lleva mucho tiempo y arduo trabajo.

Sin embargo, para comprender la posición estética de Arriaga, que no tuvo tiempo de cambiar con rumbo a la independencia creadora, es conveniente una referencia a las actitudes musicales de sus maestros, de cuyas orientaciones jamás alcanzó a salir, pese a que su capacidad apuntaba unas dimensiones muy superiores a la de sus mentores.

Pierre Marie François de Sales Baillot nació en Passy, el 1o. de octubre de 1771, si bien parece haber sido impermeable al pensamiento de la Revolución Francesa. Mostró el usual talento precoz de los músicos profesionales. A la muerte de su padre, acaecida cuando tenía doce años de edad, fue puesto al cuidado de Monsieur de Boucheporn, un alto funcionario del gobierno francés, quien lo mandó a Roma para ser educado junto a sus niños. Entre 1791 y 1795 probó en París algu.. nas de sus inquietudes vitales, primero como violinista de la orquesta del Teatro Feydeau, luego como funcionario del Ministerio de Finanzas y finalmente como miembro del ejército.

Pero su alma estaba en la música, en el violín concretamente, desde que tenía diez años de edad y había oído tocar a Viotti (1755-1824), así es que renovó su celo en el estudio del instrumento, estudió composición con Reicha (1770-1836) y Cherubini (1760-1842) y después de lograr un señalado éxito al tocar un concierto de Viotti, fue nombrado profesor del Conservatorio, entonces recién fundado. En 1802 ingresó a la orquesta privada de Napoleón y entre 1805 y 1808 logró enormes triunfos en Rusia, con giras de conciertos en calidad de violinista.

Baillot fue el último de la escuela clásica de violinistas de París y tal vez el más purista de todos ellos, que se caracterizaron por un sonido potente - tal vez algo duro- y una gran exactitud en su afinación (se dice que Baillot se tapaba la cara con las manos cuando escuchaba a Paganini tocar sus típicas instituciones de armónicos dobles, pizzicati de la mano izquierda y pasajes en staccato): Junto con Kreutzer (1766-1831) y Rode (1774-1830) -dos de los más prominentes alumnos de Viotti- escribió un método para violín, y en 1834 publicó su L'art $d u$ violon, que todavía está en uso, pero de sus composiciones no hay nada que subsista. Su especial capacidad en la música de cámara se probó en una serie de conciertos presentados en París en 1814, que le 
ganó las más entusiastas alabanzas de Spohr (1784-1859) y Mendelssohn. Ello es particularmente sugestivo dado que los Tres cuartetos de su alumno Arriaga son su obra más importante después de la Sinfonia en re mayor. Escribió quince obras para violín y orquesta (nueve conciertos, una sinfonía concertante y obras diversas, entre las que se cuentan dos aires rusos), cerca de ochenta obras de cámara (hay once aires rusos) y una de ellas, los Tres cuartetos, op. 34, compuesta en 1805, podría ser un antecedente para la motivación posterior de la obra similar de su alumno Arriaga. Hubo en Baillot cierta capacidad literaria, que sólo se hizo presente cuando la muerte de sus amigos o artistas admirados le hizo escribir prosa. En 1825 publicó un obituario para Viotti y en 1814 había publicado uno similar para Grétry (1741-1813), además de componer, en 1815, su Aire de Grétry variado en trio, op. 39, como un homenaje al músico fallecido. Baillot murió en París, el 15 de septiembre de 1842, dieciséis años después de su más brillante alumno ( 35 años menor que él). Si no escribió comentario alguno acerca del fallecimiento de Arriaga, quien sí publicó un apasionado y lírico artículo necrológico fue su otro maestro, el entonces célebre y poderoso François Joseph Fétis, que había nacido en Mons, el 25 de marzo de 1784 .

Fétis fue musicólogo, crítico, profesor y compositor. Su extensa labor en tantos campos lo hizo una de las personalidades musicales más importantes del siglo pasado, ya que sus puestos administrativos le permitieron influir en todo el mundo musical europeo. Su biographie universelle des musiciens et bibliographie générale de la musique (1835-1844), fue la primera obra moderna del género y es posible que sus ideas estéticas, un tanto reaccionarias, hayan tenido algo que ver con las actitudes populares en relación a la música nueva. Fue, sin embargo, un músico que a los nueve años de edad había escrito un concierto para violín, estrenado por su padre, quien era un músico profesional. Estudió en el Conservatorio de París con Boieldieu (1775-1734) y con J. B. Rey (1734-1810), quien enseñaba la armonía ciñéndose muy estrictamente a la teoría de Rameau (1638-1764).

En 1806 se casó con la joven hija de un acaudalado editor y en 1807 ganó el segundo premio de composición del Conservatorio, el que se llamaría posteriormente el Premio de Roma. Pero en 1811 la familia de su esposa quedó arruinada y hubo de irse de París y ganar su vida como profesor de armonía y canto, además de aceptar un puesto de 
organista en una iglesia. En 1818 volvió a París y sobrevivió como maestro de fuga y composición en el Conservatorio, del que fue nombrado catedrático en 1821. Antes había escrito diversas óperas cómicas y todo tipo de variaciones y fantasías en estilo popular, fácilmente comercializable en aquella época. En 1824 se publicó su Tratado de contrapunto y fuga, y en 1826 alcanzó un gran éxito con su ópera cómica La vieille. El mismo año inició su trabajo como bibliotecario del Conservatorio, puesto que desempeñó durante cuatro años.

Fétis fue nombrado director del Conservatorio de Bruselas en 1833 y se volvió la pieza dominante de la vida musical belga, ya que además de dirigir conciertos era el maestro de capilla del rey Leopoldo I. También escribia en la Revue et Gazette Musicale, publicación surgida de la fusión (en 1835) de su propia Revue Musicale, que había fundado en 1827, y de la Gazette Musicale de Paris. Fue un hombre muy trabajador que permaneció activo hasta su muerte, ocurrida en Bruselas el 26 de marzo de 1871. Su catálogo de obras nos muestra 27 tratados de música, de los cuales siete son métodos para el aprendizaje de diversas áreas $\mathrm{e}$ instrumentos musicales, así como un mínimo de siete óperas, ocho obras vocales polifónicas, tanto sacras como profanas, alrededor de quince composiciones de música de cámara, unas diez obras para piano y cerca de 70 piezas para órgano, además de dos conciertos para piano y orquesta, una fantasía sinfónica para órgano y orquesta, un concierto para flauta y orquesta y dos sinfonías. El estilo de sus obras es francamente reaccionario y la influencia de Haydn y el primer Beethoven es muy claramente detectable. Pero su inventiva no es la seca erudición de un limitado enseñante, sino que tiene una verdadera frescura y originalidad, un tanto apoyadas por la eficiente técnica de composición de la que siempre hizo gala.

Fétis no creía que la música representaba un proceso de continua mejora, sino que pensaba en una evolución de posiciones y no de calidades. Su idea "el arte no progresa, simplemente cambia" resulta mucho más avanzada que la mayoría de sus resultados profesionales, como compositor y como maestro. Fue el primero en mostrar el vínculo existente entre las diversas escuelas flamencas de Dufay $(c$. 1400-1474) y Binchois (c. 1400-1460) a través de Obrecht (c. 14511505), Tinctoris (1436-1511), Ockeghem (c. 1425-1497), Josquin Desprez (c. 1440-1521), Pierre de La Rue (c. 1460-1518), Willaert (c. 1490. 1562) y Lassus (c. 1532-1594). Su enciclopédica mentalidad le hizo in- 
tentar una síntesis total del conocimiento musical del pasado; pero esa esperanza no era sino una ilusión metafórica, tal vez basada en el particular criterio del siglo xIx en relación con la tarea del conocimiento humano. Sin embargo, su concepto básico acerca de la estructura de la historia de la música, más relacionado con la secuencia de los eventos estéticos de la música como el desarrollo de un lenguaje artístico que con los detalles musicales de biografías individuales, resultó fundamental en la formación del criterio musicológico moderno. También fue uno de los fundadores de la etnomusicología comparada a través de sus estudios de música folklórica europea y ajena al continente. En 1867 presentó una monografía en un congreso de la Sociedad de Antropología de París, el primer punto de contacto entre los dos campos del conocimiento.

El conocimiento histórico de Fétis y su concepto de la importancia de la música antigua fue decisivo en los criterios que adoptó para su labor pedagógica. Su Método de los métodos de piano, escrito en colaboración con Moscheles (1794-1870), postuló la idea -en contra del criterio dominante en la época- de que el virtuoso no podía ya limitarse a tocar su propia música, sino que tenía que tocar la gran música del pasado y la buena música del presente y estudiar diversos enfoques técnicos requeridos para tocar correctamente las obras del pasado y traerlas de nuevo a la vida del presente. Actitud curiosamente nueva en un hombre muy conservador. Así es que publicó ejemplos de Bach, Scarlatti, Clementi, Hummel, Beethoven y Liszt en su obra.

Su concepto de la armonía se basaba en una comprensión sociolón gica, al contrario de la escuela de Rameau, en la que fue educado, que mantenía el origen de la armonía en las leyes de la naturaleza. Fétis creía que la naturaleza proveía únicamente de sonidos y que éstos carecían de significado hasta que se ordenaban en escalas, único medio por el que se podía hacer música (jle habría encantado conocer el pensamiento de John Cage!). En este punto, Fétis daba el gran salto a la modernidad y uecía que esa organización escolar variaba en significado y expresión de una cultura y de una época a otra. Por ello, el estudio de la armonía no producía leyes inmutables y definitivas, derivadas directamente de leyes naturales, ya que estos enfoques cambiaban con el tiempo. De este modo clasificó cuatro periodos en la historia de la armonía: el estrato unifónico, perteneciente a la primitiva modalidad, el estrato trasfónico, característico de la tonalidad clásica (ar- 
monía cromática de primer grado); el estrato pluritónico, apto para la aparición de mayores posibilidades de modulación, y el estrato omnitónico, en el que la ambigüedad tonal sería manejada sistemáticamente para obtener una modulación constante, lo cual permite ver que -por muy al margen que su emotividad se mantuviera- podía ver claramente las más avanzadas tendencias contemporáneas del arte musical.

Este eje de la familia y los maestros permite sin duda comprender la estética del muchacho Arriaga y adquirir una clara visión de la orientación musical del compositor, novel y a la vez talentosísimo, que dejó una obra de altos vuelos, capaz de probar su truncada capacidad creadora.

En el curso de sus primeros años en el Conservatorio, Arriaga compuso tres cuartetos de cuerda, de admirable factura, que publicó en París en 1824. con una cariñosa dedicatoria a su padre, y que fueron la única obra suya que se imprimió durante su vida. La influencia $-\mathrm{y}$ tal vez la mano- de Baillot se adivina entre la sólida realización que los cuartetos significan y que son la causa fundamental de su reputación como compositor, ya que casi todos los músicos y aficionados a la música de cámara los conocen o (al menos) han oído hablar de ellos. Durante el breve lapso de vida que le quedó después de sus cuartetos se dedicó intensa y ardorosamente a la creación de música y produjo toda una serie de obras. Después de graduarse en el Conservatorio su nivel de trabajo a poyaba el mote de "El Mozart Español", con que varias personas se referían a él y que se ha pasado - -a nivel de leyenda cultural- a la España del presente. Compuso una serie de cantatas sobre temas clásicos que eran populares en la época, del tipo que solía ganar los concursos del Premio de Roma (¿tal vez con propósitos futuristas?), a más de canciones, una obertura, una misa, un Stabat Mater. Las cantatas fueron de ciertas ambiciones: All'Auro$r e$, para tenor, bajo y orquesta; Erminia, titulada escena lírico-dramátiCa, para soprano y orquesta; Edipo, para tenor y orquesta; Medea, aria para soprano y orquesta y Agar, llamada escena bíblica para tenor, soprano y orquesta y un adelanto del género sacro-profano que llevó a Rubinstein al trabajo en sus oratorios-bíblicos. También hubo música para piano y un poco antes del fin de su corta vida, la Sinfonía en re mayor "a gran orquesta", obra maestra en su género, clase y momento, además de su derecho de paso a la posteridad y la confirmación de que 
los cuartetos de cuerda no habían sido una simple casualidad. Esta obra probablemente no se tocó en vida del autor y permaneció inédita hasta 1933, cuando apareció en una hermosa edición, que lleva en su carátula una ilustración de la estatua en bronce de Arriaga, hecha por Miguel García Salazar, en 1908. Posteriormente, la Junta de Cultura de Vizcaya lanzó otra edición, que incluso alcanzó a través de la no siempre afortunadamente célebre casa Kalmus, una edición en el mercado norteamericano.

Arriaga fue siempre una persona frágil, de mala salud y disposición anímica un tanto melancólica. Estaba enfermo y su enfermedad tuvo un resultado fatal. Parece que murió en Marsella, ciudad a la que bien pudo haber ido en busca de un alivio, según lo preconizado por los médicos franceses de la época ("cambio total de aires y de ambiente"), si bien esta parte de su corta biografía es un poquitín borrosa, pero estamos ciertos de que fue sepultado en una tumba ordinaria del cementerio de Montmartre, diez días antes de su vigésimo cumpleaños, el 17 de enero de 1826, no demasiado lejos del sitio que iba a recoger los restos mortales de Berlioz.

Los logros artísticos de Arraiga consiguieron disparar el patriotismo cultural español a gran altura, dentro y fuera del país vasco. Las primeras obras que el Cuarteto Nacional de España tocó en los primeros conciertos con música de autores españoles que ofrecieron después de la Guerra Civil, contenían los tres cuartetos de Arriaga, que fueron recibidos con gran entusiasmo, como una fina representación del espíritu clásico español, por más que tengan mucho de un producto francés. $\mathbf{E l}$ entusiasmo por Arriaga ha producido más bien la edición de su música que la comprensión de su estética. La leyenda de uñ Mozart español, aumentada por la impresión de su solitario y poco formal entierro, ha capturado la imaginación de muchos, que ven más el aspecto exterior de su biografía, incluyendo la trágica cuestión de su prematura muerte, que los puntos interiores de su música, más válidos e interesantes que la novela de su vida. En Bilbao hay un Teatro Arriaga, frente al que se halla una estatua del juvenil compositor. En 1933, alrededor de la develación del monumento y el bautizo del teatro, se instauró la Comisión Permanente Arriaga, con el objeto de publicar y difundir su música, y la Junta de Cultura de Vizcaya se ha encargado de financiar diversas ediciones de sus obras.

El contraste de la vida y estética de Arriaga con el de su colega 
paralelo Héctor Berlioz no puede ser más grande, ya que las actitudes iconoclastas muy difícilmente cabrian en el universo estético del español. Berlioz fue un revolucionario integral, Arriaga un conservador por excelencia; Berlioz inculcaba la visión de mundos nuevos y Arriaga tendía a la recreación de instituciones antiguas. No hay modo de saber si la diferencia de sus enfoques está en la temprana muerte de Arriaga, si bien parece más lógico pensar que -al igual que en el caso de Franz Danzi (1763-1826) - Arriaga hubiera sido un moderado desde el punto de vista estético, aun si hubiese muer to a edad muy avanzada. La potencia del genio creador de Berlioz, tal vez el músico más avanzado de todos los tiempos, parece absolutamente singular, pero no se puede disertar sobre lo que pudo haber sido y no fue. Arriaga tenía una capacidad totalmente fuera de la común, pero la influencia de Fétiz y todo lo que produjo apuntan hacia una estética definitivamente arcaizante, cuyo autor paralelo -Schubert- tampoco vivió lo suficiente para poder desarrollar todas las consecuencias artísticas de sus tendencias musicales.

Arriaga vivía en la adoración de sus padres y maestros, y la motivación de aprobación y recompensa, que lo hacía deseado, comprendido y realizado, no casaba con el ideal revolucionario de Berlioz. El autor clave para entender la música de Arriaga es Schubert, pese a que Mozart y Rossini puedan venir a la cabeza cuando se habla del español. Su obra parece la consecuencia estética de Haydn y Danzi, y en su fondo están más Hasse y Graun que Gluck, Handel y Bach. Si bien todo en Arriaga es temprano, primero la sinfonía, producto de sus últimos meses de vida, habla de la posibilidad del paso a otro estrato evolutivo. Con quien no se puede comparar, a menos que se admitan la pobreza y la palidez como patrones para realizar un contraste tan elemental, como arbitrario, injusto y absurdo, es con Mozart. Por las mismas razones que no se compara un estero con el océano Pacifico, por más que ambos tengan agua. Mozart fue un caso único y la cercanía de Arriaga con aquella cumbre no existe. Ese intento de acercarlos parte de una metáfora que no sólo es fácil, sino banal y no existe la menor justificación para realizarla. El uso de la misma debe considerarse basado en la precipitación y la ignorancia ya que incluso mentes y obras como la de Gaulois (1811-1832) tienen una gran distancia con el caso Mozart. No basta morir joven, vivir pobre, ser enterrado sin ceremonias o crear alguna obra de arte para poder medirse con 
Mozart. Esa posibilidad proviene de otros estratos, de otros factores, diversos de la casualidad biográfica o anecdótica.

En la obra de Arriaga, la pertenencia al enfoque clásico parece muy evidente, si bien el contenido y alcance de lo clásico resulta muy discutible y espinoso. El término "clásico" ha sido usado en relación con una gama muy grande de música de diversas culturas. Sus dos acepciones principales son la de modelo de excelencia y la de posición opuesta a lo "romántico", si es que esta última palabra -de acuerdo a Goethe- se comprende como algo con un contenido desordenado y morboso. En su primer significado, la palabra se ha usado en una gran diversidad de casos, desde los motetes de Josquin Desprez, La consagración de la primavera, de Stravinski pasando por los lieder de Schubert, las misas de Palestrina, los oratorios de Handel, las suites de Couperin y los concerti grossi de Corelli. Sin embargo, en el caso de Arriaga, ese aspecto clásico debería vincularse con el llamado clasicismo vienés.

Ese término suele referirse al grupo de obras formado por Haydn, Mozart y una parte del trabajo de Beethoven. El concepto de que tales compositores integraron un periodo clásico aparece en los tratadistas alemanes del siglo xIx, como analogía de los clásicos de Weimar, momento creado principalmente por Goethe y Schiller. Blume fue quien extendió las fronteras de este periodo desde la mitad del siglo xviII hasta los primeros treinta años del siglo xIx, con el objeto de poder abarcar en tal clasificación a la obra de Schubert. Él fue quien negó enfáticamente la posibilidad de hallar completa unidad estilistica entre la época comprendida desde la muerte de Bach hasta 1827 (año del fallecimiento de Beethoven). Esta idea suponía la existencia de un período estético que abarcaba la homofonía de Haydn y los periodos segundo y tercero de Beethoven, cuando las formas clásicas principiaron a borrarse, a ser superadas $y$, finalmente, a desintegrarse.

El hecho de que hay un sistema clásico de expresión común a Haydn, Mozart y parte de la obra de Beethoven, es más fácil de comprender que la idea de un periodo clásico. También se acepta con facilidad el que se considere a Haydn como el creador básico y principal de dicho lenguaje musical. Mozart siguió estrechamente la estética de Haydn, sobre todo en la década de 1770 con respecto de sus cuartetos y sinfonias. Posteriores elementos evolutivos, que sólo puede calificarse de visionarios (como los conciertos K. 466, 467 y 491 ), pertenecen a la 
zona enigmática de Mozart, aquel campo en el que sólo hay conjeturas y que nos lleva a preguntarnos hasta dónde habría llegado Mozart de haber muerto a los 70 años de edad. ¿Se habría completado la colosal evolución estética y estilística que apuntan las obras de sus últimos tres años de vida? ¿Habría sido Mozart el puente entre los clásicos y Berlioz? ¿O hubiera sido simplemente la afirmación de la estética clásica? Por lo pronto, seis cuartetos de Mozart dedicados a Haydn son una muy elocuente prueba del compromiso mozartiano con la ideología estética del gran Haydn. Otras característcias y elementos de la síntesis que los dos inmensos clásicos lograron fue la utilización de la dinámica y la textura y el color de la orquesta con un enfoque temático, tal vez como consecuencia o legado de la escuela de Mannheim. La forma de manejar el ritmo, sobre todo el ritmo armónico para lograr formas de gran envergadura, y el empleo de la modulación para discurrir ámbitos más amplios de tensión y relajamiento, que mucho después (en tiempo y en estética) llevaría Mahler al extremo máximo, son características definitivas de los dos clásicos, usadas y desarrolladas por Beethoven.

En el campo de la disciplina formal puede también retratarse a los dos gigantes. Su capacidad técnica y maestria formal son evidentes, a un grado sumo. Su facilidad de escritura, fluidez en el canto, y su éxito y gusto al permanecer dentro de las convenciones aceptadas por su lógica musical, o incluso su aptitud para violentarlas lógicamente, señalan también lo que se ha llamado la actitud clásica, un elemento de fidelidad a las convenciones y elementos que iban a complacer al público y a guiarlo y ayudarlo en la tarea de comprender la música, gustar de ella y recorrer el camino de la comunicación con el compositor. El artista clásico, sin que importen su campo ni su época, produce de acuerdo con su público, trata de colmar sus expectativas y satisfacer sus anhelos, sin que le preocupe producir resultados artísticos agradables de primera intención o someterse a las exigencias estéticas de la sociedad en un momento determinado.

Es en esta fácil y fluyente relación estética con las esperanzas del consumidor y destinatario del arte que logramos una de las explicaciones de la casi absurda fecundidad de Mozart y Haydn, pues las centenas de obras con las que hipertrofiaron la riqueza musical del periodo clásico vienés, acusan la más absoluta y total maestría en todo género concebible en su era, y ello los convierte -sobre todo en el caso de Mozart- en los últimos autores con verdadero derecho a lla- 
marse universales durante dos siglos, hasta que las angustias y restricciones al individualismo que provienen del mundo moderno, exacerbadas por la deplorable hormiguización social del universo comunista, instauraron a Beethoven y a Chaikovski en el trono de la comunicación estético-social.

Esa titánica fertilidad de los clásicos supone un enfoque rotundamente profesional en el oficio de compositor de música. La tranquila y alegre aceptación de Haydn a las convenciones de su mundo no impidió que sus contemporáneos los reconocieran como elocuentes y profundamente originales, ni ha mediatizado en forma alguna la pasmosa admiración con que los oídos contemporáneos abrimos la boca frente a maravillas de modernidad como la 45a. sinfonia, tal vez más revolucionaria - por su relación con el teatro musical- que sus obras finales, tan profundas y sintéticas.

El caso de Beethoven es algo más difícil de clasificar simplemente, ya que con independencia de sus resultados artísticos en el terreno de la música visionaria y nueva, los rasgos exteriores de su personalidad lo acercan mucho a la imagen del artista romántico. El simple hecho de su ensimismamiento, que aumentó constantemente durante sus últimos años y que de muchas formas lo alejó del público, lo aparta de uno de los ideales típicos del artista clásico, esto es, la facilidad e inmediatez en la comunicación con la gente. El tipo del artista romántico creado por Richter y perfeccionado por Hoffmann, aislado, ilimitado, extravagante, impulsivo, un tanto salvaje, poseedor de muchisimas características que se ponían de moda a través de los jóvenes literatos alemanes, esclavo de las oscuras fuerzas de su propio genio, se acopla casi perfectamente con Beethoven y ello contribuyye a oscurecer su perfil estético, a pesar de que cualquier cosa que el artista romántico percibió -en todo terreno- como imaginativa, colorida, conmovedora o fantástica (incluyendo a la música de Haydn o Mozart) era inmediatamente aceptada y etiquetada como romántica. La decreciente pro. ductividad de Beethoven en sus últimos años señala otra de las grandes brechas entre las actitudes clásicas y la postura beethoviana, ya que su constante y siempre creciente inquietud por ser original y distinto, la búsqueda de un mundo diverso y un universo entero en cada obra, no sólo diferente sino autosuficiente, capaz de expresar un lenguaje individual y elocuente, nacido de la lucha y la tormenta interior y emparentado con los más herméticos símbolos de la mente, nos permite una 
clara percepción de una diferencia estética y profesional muy grande con los clásicos.

Lo evidente, es el alto grado de homogeneidad musical que prevaleció en Europa durante el cambio del siglo xvirr al xrx, el cual permitió poner aparte las diferencias en los estilos musicales y enfatizar el parecido de la música que se hacia en Berlín, París, Nápoles. La formación de un estilo cosmopolita, que se cultivaba en todas las grandes capitales, tuvo un efecto difusor extraordinario y a través de la distribución de obras impresas y manuscritos alcanzó todos los rincones de la civilización occidental. El ejemplo de la Sinfonia de Sarrier, posiblemente creada en Morelia, Michoacán (entonces Valladolid), en el estilo italiano más puro y perfecto es un caso típico para ilustrar cómo en una ciudad quasi villorrio, alejada en más de un sentido de los grandes centros de civilización, el espíritu y la técnica de los clásicos permitieron la producción de una obra casi perfecta.

El clasicismo de Arriaga, evidente y aumentado en Haydn, se acerca mucho más a la estética de Schubert que a las tormentas beethovianas o las pasiones del último Mozart. Schubert, a pesar del salvaje primer movimiento de la Sinfonia inconclusa, está más cerca de Haydn que de Beethoven, pese a su admiración personal por el titán alemán, muy explicable en cualquier músico de mediano talento e inevitable en un genio de la talla de Schubert. Por mucho que su prematura muerte haya truncado todas sus posibilidades expresivas y estéticas, Arriaga resulta ser un músico cuya expresión melódica tiende a Schubert (si bien su armonía nunca se complicó tanto) a pesar de que lo más seguro es que no haya existido una influencia directa del alemán sobre el español. La Sinfonía de Amiaga, con todo su espontáneo rigor formal, tiene algunos puntos débiles en cuanto a la fluidez de su trama melódico-armónica, y la comparación que se ha llegado a hacer con la Primera sinfonia de Bizet no pasa de ser un recurso de perezoso intelectual. De cualquier forma, es un punto algo injusto, pues si bien la capacidad de Arriaga es absolutamente indudable, un genio como el de Bizet aparece sólo una vez en cada generación y nada apunta en Arriaga a un nivel de esa categoría, que podría englobar a calidades como la de Mendelssohn. El ideal de Arriaga parecería estar más cerca de Danzi que de Mendelssohn, y en ese músico hallamos un parangón y una medida excelente para el español. Lo indudable -y lo doloroso-es que el muchacho tuvo una capacidad y unas posibilidades extraor- 
dinarias y que nada podemos inferir de lo que hubiera hecho en su vida futura. Lo que existe, rotundo e innegable, es la obra, que tiene el más elevado interés.

Las primeras obras que compuso Arriaga carecen de trivialidad, incluso en sus formas cortas. En las obras de mayor alcance hallamos una consecuencia de las formas italianas de pequeño calibre, cuya imitación era inevitable, dada la circunstancia de la ciudad donde vivía y de la extrema popularidad de ese tipo de música en España. Su música de cámara suele consistir de partes de alto virtuosismo para el violín, que se proyecta contra una textura acompañante, tal vez para poder lucir la capacidad del autor en el terreno de la ejecución instrumental. En las últimas obras de Arriaga, las que le dan su derecho al paso de la memoria histórica, a saber los cuartetos y la sinfonía, se puede notar claramente el efecto y consecuencia del entrenamiento recibido en el Conservatorio de París, no sólo en cuanto a la mayor perfección técnica y pulimento formal, sino respecto de la confirmación, afirmación y fijación de su actitud estética. Su manejo de los recursos contrapuntísticos es bastante fácil y su empleo -si bien algo ingenuo- es abundante. El punto clave de su obra, sobre todo en la sinfonía, es la capacidad intuitiva de síntesis que demostró tener. Esa síntesis se refiere a su habilidad para conservar un elemento expresivo personal e individual dentro del riguroso marco formal y estético en el que se le obligaba doctrinariamente a crear; su aptitud para lograr una corrección estilística inscrita en un ámbito de formal elegancia y mantener el elemento de comunicación que requería la ideología clásica a la que se sometió, por más voluntarioso que haya sido su intento. Esa posibilidad, tan buscada por músicos como Fétis y tan loada en la atmósfera estética de su momento en el Conservatorio de París, era el punto culminante de las esperanzas profesionales e ideales artísticos de la estética de sus maestros, y el hallar quién pudiera componer de acuerdo a la cerrada y rigida ortodoxia musical que se practicaba en ese ámbito era el punto cumbre de la buena suerte. En gran parte, tal fue la causa del gran sentimiento de pérdida que sufrieron los tradicionalistas encabezados por Fétis a causa de su fallecimiento; la extinción de una esperanza de una promesa de que alguien podría lograr lo que ellos habían buscado en vano: la composición totalmente correcta pero también atractiva e interesante, muy bien tipificada en la 
Sinfonía, obra con un pulimento cercano a la perfección y con una belleza obvia e inmediatamente perceptible.

La música de Arriaga permaneció en el olvido durante muchos años. La exaltación del nacionalismo español en los últimos años del siglo xix contribuyó a su exhumación, ya que no existía ningún músico español posterior a los grandes renacentistas que hubiera logrado reconocimiento indiscutido fuera de España. La enorme fama de Fétis fue tal vez la causa inicial del interés por Arriaga en España. Además, la figura del juvenil y malogrado compositor satisfacía muchas facetas del idealismo romántico, en virtud de la esperanza que un talento así podía despertar, truncada trágicamente por una muerte demasiado temprana. Ello contribuyó a la deformación de su figura y a la transformación (o más bien a la metamorfosis) de un músico capaz en una especie de santo artístico, de mártir musical mítico, centro involuntario de un culto cuya figura capital era su juventud y no su obra, comparado constantemente con Mozart y con otras víctimas de una muerte prematura, hecho que es maldición personal, a veces tragedia estética y en algunas ocasiones una ventaja de carácter artístico y profesional para quienes casi se podría calificar de beneficiarios de su propio fallecimiento. No se examinaba - ni se oía - su obra, tan sólo se atendia a su destacado desarrollo en el Conservatorio de París, a los elogios de Fétis y al hecho de que había muerto a los diecinueve años de edad.

En Bilbao, el culto llegó lejos, si atendemos al teatro nombrado con su apelido y al monumento erigido a una persona de cuya música (y por lo tanto cuyos méritos) nadie conocía lo suficiente, si es que algo se habia escuchado alguna vez. Se han publicado varios estudios acerca de Arriaga, pêio la mayoría son alabanzas rapsódicas que no atienden a puntos artísticos, cuestiones estéticas o razones musicales. Algunos ni siquiera parten del análisis o audición de su música, como esencial punto de partida previo a la entrega desmedida al ditirambo laudatorio. Por ello se puede afirmar que Arriaga es todavía campo muy poco explorado, en el que la investigación desapasionada, seria, profunda y dedicada tiene todavía cosas por decir.

Leningrado, URSS, mayo de 1982 
obras de Juan Crisóstomo ARriaga

\section{MÚSICA DE CÁMARA.}

Nada y mucho: ensayo en octeto, en fa mayor, para dos violines, viola, vio. loncello, contrabajo, trompeta, guitarra y piano, 1817. Publicado en Bilbao, en 1929.

Tema variado en cuarteto, en fa mayor, para cuarteto de cuerdas, op. 17, 1820. Publicado en Bilbao en 1928.

La húngara, para violín y contrabajo.

La húngara en cuarteto, variaciones, en re mayor, para cuarteto de cuerdas, op. 23, 1822. Arreglo para violín y piano (ddel autor?) publicado en Bilbao en 1925 .

Cuarteto de cuerdas, en re menor;

Cuarteto de cuerdas, en la mayor;

Cuarteto de cuerdas, en mi bemol mayor;

compuestos en París, en 1824 y publicados en la misma ciudad y año.

Tres estudios de carácter, para piano, publicado en Bilbao, s.f.

Romances, para violín y piano, inédita.

\section{MÚSICA VOCAL.}

Los esclavos felices, ópera semiseria en dos escenas, sobre un libreto de Comella y Comella, estrenado en Bilbao en 1820. La obertura fue publicada en Bilbao, c. 1950.

Patria, para voces y orquesta, manuscrito extraviado.

Agar, escena bíblico-dramática, en español, inédita en versión orquestal.

Romance (de Agar), para canto y piano, publicado en Barcelona, c. 1920.

Finale (de Agar), para voces y orquesta, publicada en Madrid, c. 1920.

Erminia, escena lírico-dramática basada en Tasso, en versión orquestal, publicada en Madrid, c. 1923.

Ou vais-je malhereux (recitativo) y Hélas d'une si pure flamme (aria),

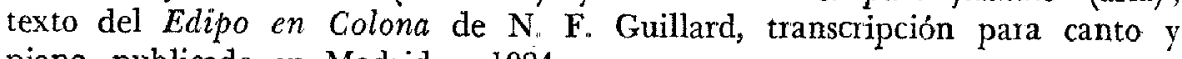
piano, publicado en Madrid c. 1924.

Hymen, viens dissiper, axia de Medea, versión para canto y piano, publicada en Barcelona, c. 1920.

All'aurora, dueto para tenor y barítono, en versión orquestal.

\section{MÚSICA SACRA} s.f.

O salutaris, tres voces con quinteto de cuerdas, publicada en Madrid (?),

Stabat Mater, tres voces con orquesta, publicado en Madrid, antes de 1924. Misa, cuatro voces, manuscrito extraviado.

Salve Regina, manuscrito extraviado.

Et vitam venturi, fuga a ocho voces, manuscrito extraviado. 


\section{MÚSICA PARA ORQUESTA}

Obertura en fa menor, para noneto (flauta, dos clarinetes, dos trompetas, dos violines, viola, violoncello y contrabajo), op. 1 (dedicada a la Academia Filarmónica de Bilbao), 1818, publicada en Bilbao, s.f.

Obertura a Los esclavos felices, mencionada arriba.

Marcha militar, para banda, manuscrito extraviado.

Sinfonia, en re mayor, Bilbao, c. 1950.

\section{Discografía}

3 Cuartetos (completos) Golden Crest S-4061

Cuarteto Phoenix

Obertura a Los esclavos felices HNH-4001

Jesús López Cobos, Orquesta de Gámara Inglesa

Sinfonía en re mayor HNH-4001

Jesús López Cobos, Orquesta de Cámara Inglesa

Jorge Velazco, Sinfonietta R.I.A.S. Schwann-Serie Musica Mundi

Tema y variaciones Golden Crest S-4061

Cuarteto Phoenix. 


\section{Bibliografía}

Adrer, G., "Die Wiener Klassische Schule", en Handbuch der Musikgeschichte, Frankfurt, 1924, p. 694.

Bücken, E., Die Musik des Rokokos und der Klassik, Potsdam, 1927.

Cudwortu, C., "Baroque, Rococo, Galant, Glassic", en The Monthly Musical Record, LXXXIII, 1953, p. 172.

ENGer, H., "Die Quellen des Klassischen Stiles", en International Musicological Society Congress Report, VIII, New York, 1961, p. 285.

Engel, H., "Haydn, Mozart und die Klassik", en Mozart-Jahrbuch des Zentralinstituts für Mozart-forschung, 1959, p. 46.

Eresalde, J. de Los esclavos felices, ópera de J. C. Arriaga: antecedentes, comentarios, argumentos y algunas noticias bibliográficas, Bilbao, 1935.

FEDER, G., "Bemerkungen über die Ausbildung der klassischen Tonsprache in der Instrumentalmusik Haydns", en International Musicological Society Congress Report, New York, 1961, p. 305.

FÉts, F. J. "Obituario", en Revue Musicale, II/4, París, 1829, p. 199.

Figuerido, C. A., El arte y la mente del músico J. C. de Arriaga, Bilbao, 1948.

Finscher, L., "Das Originalgenie und die tradition: Zur Rolle der Tradition in der Entstehungsgeschichte des Wiener Klassischen Stils", en Studien zur Tradition in der Musik: Kurt von Fischer zum 60 Geburtstag, Munich, 1973 , p. 165.

Finscher, L., "Zum Begriff der Klassik in der Musik", en Musikwissenchaftliches Jahrbuch, 1966, p. 9.

FRYKxUND, D., "Eine Schwedische Sammlung von Briefen von und an Fétis", en International Musicological Society Congress Report, I, Lieja, 1930, p. 113.

Gollmick, C., Herr Fétis, Vorstand des Brüsseler Conservatoriums alls Mensch, Kritiker, Theoretiker and Componist, Leipzig y Bruselas, 1852.

Goldsmidr, H., "Über die Einheit der vokalen und instrumentalen Sphäze in der Klassischen Musik", en Musikwissenschaftliches Jahrbuch, 1966 p. 35.

GREgoir, E., L'art musical en Belgique sous les regnes de Léopold I et Léopold $I I$, Bruselas, 1879.

GurLITT, W., "Franz-Joseph Fétis und seine Rolle in der geschichte der Musikwissenschaft", en International Musicological Society Congress Report, $\mathrm{I}$, Lieja, 1930, p. 35.

MeNDELssohn-Bartholdy, C., Goethe und Felix Mendelssohn-Bartholdy, Leipzig, 1871.

Pierre, G., Le conservatoire National, París, 1900.

Rosen, C., The Classical Style: Haydn, Mozart, Beethoven, New York, 1971, 2o. vol., 1973. 
Soccanet, P. y otros, "Quelques documents inédits sur P. Baillot", en Revue de Musique, XX (1939), p. 71 y XXII (1943), p. 15.

Spoнr, L., Selbstbiographie, II, Göttingen, 1861, p. 129.

Tischrer, H., "Classicism, Romanticism and Music", en The music Review, XIV, 1953, p. 205.

UrIarte, E. de., "El Mozart Español", en La Cíudad de Dios; Revista Agustiniana, VII/15, Madrid, 1888, p. 258. 